\title{
Network Community Mental Health Care in North-West Derbyshire
}

\author{
Malcolm Peet, Consultant Psychiatrist, Northern General Hospital, Sheffield; \\ formerly N-W Derbyshire Community Health Team, Whitworth Hospital, Matlock, Derbyshire
}

The community mental health movement remains an important force in American psychiatry ${ }^{1}$ and a shift towards community orientated mental health care is now being actively promoted in Britain. ${ }^{2}$ Nevertheless, concepts of community mental health care are not clearly defined, and the term has been variously misused, as a label applied to existing facilities without real change in philosophy, as a political justification for closing large mental hospitals, and as a platform for the propagation of anti-medical ideology. The development of community orientated services involves a change in role for the psychiatrist, which many find difficult to accept. ${ }^{3}$ Psychiatrists have been warned that they are at risk of being left behind in the current moves towards community mental health care in Britain. ${ }^{4}$

There are two broad conceptual models of community care. One model popular in Britain can be seen as an extension of the hospital into the community. This model depends upon such facilities as day hospitals and hostels and clinics in general practice (GP) settings. Tyrer ${ }^{5}$ has described this as the 'hive system', the hive representing the hospital as the centre of activities. The alternative model begins in the community and emphasises the development of a network of community resources involving people with helping skills, both professional and non-professional. Hospital facilities are seen as one available resource in this network, but not the dominant one. This can be termed the 'network system' of community care.

In N-W Derbyshire, we have set out to develop a service on the network model. Progress until mid-1985 (when the author left the service) is described in this report, and the implications for psychiatrists of such a service are discussed.

\section{Ideology}

The core of our service is a community based multidisciplinary team, with emphasis on a more egalitarian relationship both amongst professionals and between professionals and clients. The team has no formal leader, this function being assumed by whoever is most appropriate at the time and in the circumstances. Decisions are reached by consensus. The medical model of treatment is seen as one valid approach for some clients, but not the dominant one. The team psychiatrist is responsible for the proper applications of the medical model, but other team members are autonomous when they apply social, psychological or other non-medical interventions. Diagnosis is seen as a tool for the proper application of medical treatment, but not normally as an explanation of the problem. Help given to an individual focusses on the fit between the client and his environment, and on the client's perception of his own needs. Help is offered in a local setting and is aimed at minimising the need for hospital admission. Importance is placed on the integration of all relevant available services, on the development of self-help groups, and on the involvement of clients and other members of the community in service planning.

\section{The district}

Derbyshire County is divided into two Health Districts, North and South (Fig. 1). Mental Health Services for the North Derbyshire district (population 356,825) are centred in Chesterfield. N-W Derbyshire is one sector of the North Derbyshire district and has a total population of 44,974 . The sector is mainly within the Peak District National Park and is a rural area covering some $\mathbf{4 0 0}$ square miles. The main population centre is Matlock $(20,575)$ followed by Bakewell $(4,210)$ with the remaining population scattered in smaller villages and farms. The area is relatively prosperous, the 1981 census showing $32.8 \%$ of persons in social classes 1 and $2,30.2 \%$ in social class $3,12.8 \%$ in social classes 4 and 5 , and $24.7 \%$ classified as retired/inactive; $63.6 \%$ of households are owner occupied, and $70 \%$ of households have at least one car.

\section{The previous service}

Until recently mental health services to N-W Derbyshire were provided from both Chesterfield and Derby, with a few patients also travelling to Sheffield. In Chesterfield, there was a small number of acute admission beds, a psychiatric day hospital, and out-patient clinics. Derby has the nearest large psychiatric hospital and has historically provided longstay accommodation for $\mathrm{N}-\mathrm{W}$ Derbyshire residents, in addition to acute admission beds, day hospital and out-patient facilities. A limited community psychiatric nursing service was provided from both Derby and Chesterfield.

During 1983 extra acute admission beds were opened in Chesterfield in a general hospital setting, and this led to a shift of acute admissions away from Derby towards Chesterfield. In the same year, the team psychiatrist developed GP out-patient clinics in Whitworth Hospital, a local GP Cottage Hospital in Darley Dale near Matlock (Fig. 1). The community mental health team was established in the latter part of 1983 with new money from Joint Funding, and was fully operational by the New Year of 1984.

\section{The present service}

The team comprises a consultant psychiatrist, a registrar in psychiatry, two community psychiatric nurses, a senior 


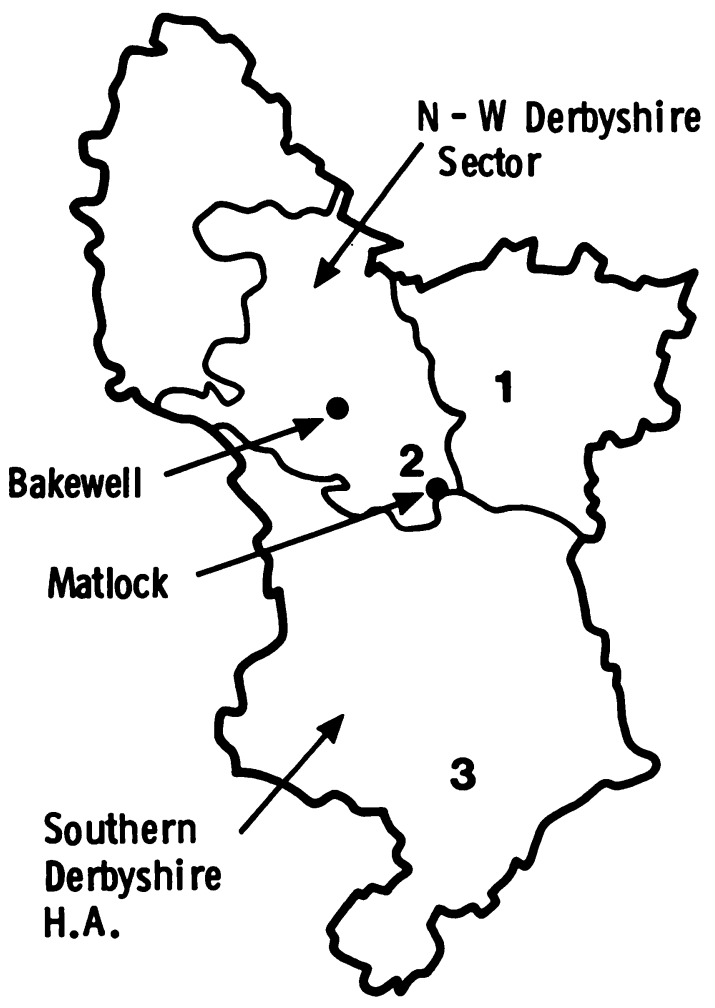

Fig. I. Map of Derbychire. 1: Walton Hospital, Chesterfield; 2: Whitworth Hospital, Darley Dale; 3: Pastures Hospital, Derby.

clinical psychologist, a social worker and two part-time secretarial staff. The team is based in the annexe of Whitworth Hospital which is well regarded and actively supported by the local community, and is seen as a nonthreatening, non-stigmatising setting. There is a communal office, waiting room, secretarial and reception area, and two multipurpose rooms, one large enough for group activities.

Conventional hospital facilities are located at Walton Hospital in Chesterfield where the team has access to six beds on one of two 28-bedded acute admission wards. The psychiatric day hospital, also based at Walton Hospital, is of limited usefulness for the N-W Derbyshire residents because of geographical distance. There is no local day care facility and no special housing provision in the $\mathrm{N}-\mathrm{W}$ Derbyshire sector.

The team is engaged in wide-ranging activities which link with other people and organisations active in the broad fields of mental health locally, and in a variety of settings outside the team base. The service is comprehensive, serving persons with either short or long-term mental health needs, with the exception of old long-stay patients who are cared for in the Pastures Hospital, Derby. There is no available new long-stay provision.

\section{Area of activity}

(a) Direct client services

Individual client referrals are accepted from any source but at present the great majority come from GPs. Selfreferral is acted upon but not yet encouraged, though this is seen as an important future development.

Referrals are in general accepted by the team rather than by individuals. Further information is obtained as necessary from the referring agency and after initial assessment by a team member, a key worker is allocated depending on the needs of the client in relation to skills and interests of the team members. Clients are usually seen either at the community base, their own homes or the GP surgery. Waiting time is minimal and a team member can normally respond to crises during the working day, though as yet we have no night-time or weekend cover other than from the hospital based services. Help is given either on an individual or a group basis.

Whilst direct client services are an essential part of mental health care, the team regards other areas of activity as having at least equal importance.

\section{(b) Indirect services}

Close interaction has been developed with other local statutory and voluntary agencies involved in mental health such as GPs, health visitors, social workers, counsellors and nurses at the local College of Higher Education, and volunteer organisers of self-help groups. The team has also been active in catalysing mutual support groups which are fundamental to community health. Examples of this are the 'Spectrum' group in Matlock, and a local branch of 'Tranx' a tranquilliser dependence self-help group.

Spectrum was catalysed by a community psychiatric nurse from the team together with a social worker based at the Tontine Road Mental Health Project in Chesterfield. Most initial members were previously clients of the formal mental health services but the group has now broadened its outlook as the name implies. There are regular meetings in an adult education centre and a local public house as well as in members' homes, and a great deal of informal individual contact between members. Individuals support each other at times of crisis and can call upon team members for support if necessary. The group is self determining with its own committee, and is affiliated to MIND. Similar networks are being initiated elsewhere in the sector linking in with other groups which have developed independently.

The Tranx group stemmed from an article written by the team psychologist and psychiatrist in the local newspaper, describing the problems of benzodiazepine dependence and asking for volunteers to come forward who have themselves been through the experience and who wish to help others with the same problem. Two volunteers were selected and trained in basic counselling and anxiety management skills by the team psychologist and one of these now runs a local group which is proving an effective vehicle for weaning people off tranquillisers. 


\section{(c) Planning}

A local planning group has been constituted on a broad democratic base to include all locally interested parties including mental health professionals, social workers, Community Health Council, representatives of voluntary organisations, client groups, and GPs. The planning group is encouraged to formulate needs and policies for local mental health care with the aim of influencing central planning decisions.

\section{Use of hospital facilities}

The team was established as a service development rather than a research project. It is nevertheless helpful to examine statistics regarding use of hospital facilities.

\section{(a) Referral rate}

During 1984, the first year of operation of the team, there were 230 individual client referrals, principally from GPs. This figure excludes the patients who were simply taken over by the team from the previous hospital-based service. This gives a referral rate of 7.6 per thousand population at risk, that is excluding children and the elderly for whom separate services are available. Of these referrals, $170(74 \%)$ were seen at some point by the consultant or registrar. However, about half of these were seen on only one or two occasions at the request of the GP or other team members, with advice given to the GP concerning subsequent medical management.

The consultant referral rate in $\mathrm{N}-\mathrm{W}$ Derbyshire increased from 2.8 per thousand population in 1982 to 4.0/1,000 in 1983 when local GP clinics were initiated, and increased further to $5.7 / 1,000$ in 1984 when the community team was functioning. An increased referral rate associated with provision of a local service has been reported by others. ${ }^{6}$ However, it should be noted that the previous referral rate was low, and the provision of our service simply brought the referral rate up to that described in services elsewhere.

\section{(b) Admission rate}

Admissions are normally kept easily within the six allocated beds. During 1984 there were 77 acute admissions. A further 13 patients were admitted to the Pastures Hospital in Derby and four patients to the Sheffield hospitals. These patients in general had been treated previously in Derby or in Sheffield and were therefore sent back there when they relapsed. Of the total 94 admissions, 14 (15\%) were first time admissions. No patient has been admitted to long-term hospital care during the first 18 months of operation of the team. From national statistics produced by the DHSS, the predicted number of admissions for our population and age range is 132 , of whom $32(24 \%)$ would be first time admissions. The average length of hospital stay was $20 \pm$ 17.7 (SD) days. This is comparable with experimental short stay services reported by others. ${ }^{8}$ Our short length of stay was achieved with very low usage of the day hospital, by means of intensive input in the home situation. Of the 12 patients who were admitted for the first time to Walton Hospital during 1984, four suffered from delusional depression, one from hypomania, three from acute situational crises, and four from acute decompensation of neurotic symptoms, which in two patients related partly to benzodiazepine withdrawal. Of the 12 day-hospital admissions, 10 immediately followed a period of in-patient care.

The admission rate for N-W Derbyshire was low even before a community mental health team was in operation, though this reflected a poor level of service rather than the provision of any valid alternative. Also, it had been the practice for many years for all potential admissions to be screened by a consultant, thereby preventing unnecessary admissions. We have succeeded in maintaining this low admission rate, particularly for first time admissions, despite the marked increase in referrals.

Due to the below average admission rate and short length of stay, bed occupancy was minimised. Our acute bed ratio of 0.13 per 1,000 population is less than half the current Trent Regional norm of 0.3 per 1,000 .

\section{(c) Use of physical treatment}

In 1983, the year before the community team was established, 59 applications of ECT were given at Walton Hospital to seven N-W Derbyshire residents. In 1984, the first year of operation of the team, 21 applications of ECT were given to four patients. In the first six months of 1985, only one patient received three applications of ECT. It is not clear why ECT usage has declined, though earlier intervention, ready availability of alternative modes of help, and more easily available advice for GPs regarding drug treatment, are likely ingredients.

Amongst the patients we inherited when the team was first established was a group of 11 patients diagnosed as schizophrenic who had been established on a fixed dose of intra-muscular neuroleptic drugs for at least one year and who were still living with their families. All had received their previous treatment from the hospital service in Chesterfield or Derby. Other modes of help were explored including intervention in the family situation and the development of social networks, sometimes within the setting of the Spectrum group. At the end of one year of such management, depot neuroleptic drug dosage had diminished on average by $61.2 \%$ from an average fortnightly dose of $49 \mathrm{mgs}$ down to $19 \mathrm{mgs}$ with no patient relapsing. This reflects a generally low usage of neuroleptic drugs amongst patients seen by the team.

There is evidence 9 that neuroleptic drugs are often prescribed in greater than necessary dosage. The provision of active family and social intervention gave us the courage to reduce doses of neuroleptic medication and may have contributed to the prevention of relapse.

\section{(d) Consumer survey}

All clients who within the past five years had received help. from both the community-based mental health team and 
the hospital-based service in Chesterfield or Derby, were invited to complete a questionnaire comparing the two services, and to make a global rating of the community based service on a five point scale. The response rate was $65(69 \%)$ of the 94 clients circulated, of which two forms were returned uncompleted. Clients rated the new service as more convenient ( $91 \%$ of respondents) and more friendly (71\%) with easier access to staff $(79 \%)$ than the previous hospital-based service. The global rating was similarly favourable: 23 excellent, 28 good, 8 satisfactory, 2 poor, 1 terrible, 1 no response. GPs were also surveyed and showed similar enthusiasm for the service. They felt that the service gave a shorter waiting time for appointments ( 15 out of 20 GPs), better communication with staff (18), easier availability of staff in routine situations (19) and emergencies (13), and more appropriate help for patients (17). The Community Health Council annual report for 1984 praised the service and called for similar developments elsewhere in the district. Consumer surveys of mental health services can be misleading because patients tend to report favourably on whatever service they are receiving at the time.$^{10}$ However, the overwhelming endorsement of the service by clients, GPs and Community Health Council is reassuring.

\section{Comment}

The development. of this type of service has several important implications for the future role of the psychiatrist. Firstly, it is not possible for the psychiatrist to maintain traditional hierarchical status simply by virtue of title. The argument that a psychiatrist must carry overall clinical responsibility, whilst valid in a hospital setting, dissipates in the setting of network community care. There is at present a general trend amongst other mental health professionals to resist medical dominance. This can result in splits between disciplines, with psychologists and community psychiatric nurses turning to primary care settings, and social workers setting up independent facilities. Paradoxically, insistence on medical control by psychiatrists can thus result in clients having less medical psychiatric attention than they would under our network system. Psychiatrists, because of their power and autonomy, can be very obstructive to change. For the same reasons, psychiatrists of all the mental health professionals are in the best position to lead the way in developing radical new modes of working.

The psychiatrist entering into this style of working tends to feel deskilled, and threatened by the loss of traditional role. It soon became evident that many of the mental health problems commonly seen by psychiatrists can be dealt with equally effectively by others without the need for psychiatric supervision. At the same time, there is a reduced amount of purely 'medical' work in terms of use of hospital facilities and physical treatment. The psychiatrist is tempted either to retreat in isolation into the remaining narrow medical role, or to make a virtue of feeling deskilled by adopting the generic role of 'mental health worker'. Neither development is in the best interest of the client, who has the right to skilled medical treatment as one option available in a balanced range of helping facilities. Similar areas of difficulty have been highlighted in the American Community Mental Health Centre movement. ${ }^{11}$ Little support can be found from other psychiatrists who commonly view such developments with scepticism or even outright hostility. There is nevertheless a growing trend towards this style of working, which can be stimulating and fulfilling, both personally and professionally. It is to be hoped that the training of future psychiatrists will better equip them to face this challenge.

\section{ACKNOWLEDGEMENTS}

Though written from a medical viewpoint this paper represents the work of all team members, who are: Saadi Ali, Richard Johnson, Mathew Littlewood, Steve Parsons, Malcolm Peet and Steve Thomson. Jackie Kosh conducted the consumer survey. Data on admissions to the Pastures Hospital and Sheffield Hospitals were kindly supplied by the respective Medical Records Departments.

\section{REFERENCES}

${ }^{1}$ Schulberg, H. C. \& KillileA, M. (eds) (1982) The Modern Practice of Community Mental Health. San Francisco: JosseyBass.

${ }^{2}$ Social Services Committee (1985) Community Care with Special Reference to Adult Mentally III and Mentally Handicapped People, vol. 1. London: HMSO.

${ }^{3}$ STURT, J. \& WATERS, H. (1985) Role of the psychiatrist in community-based mental health care. Lancet, 1, 507-508.

${ }^{4}$ Leading Article (1985) Psychiatry-a discipline that has lost its way. Lancet, 1, 731-732.

${ }^{5}$ TYRER, P. (1985) The hive system: A model for a psychiatric service. British Journal of Psychiatry, 146, 571-575.

6 _ SIEVENWRIGHT, N. \& WollerTON, S. (1984) General practice psychiatric clinics: impact on psychiatric services. British Journal of Psychiatry, 145, 15-19.

${ }^{7}$ Goldaberg, D. \& HuXley, P. (1980) Mental Illness in the Community. London, New York: Tavistock Publications.

${ }^{8}$ Hirsch, S. R., Platt, S. D., Knights, A. \& Weyman, A. (1979) Shortening hospital stay for psychiatric sare. Effects on patients and their families. British Medical Journal, 1, 442-446.

${ }^{9}$ TIEChER, M. H. \& BALdessarinI, R. J. (1985) Selection of neuroleptic dosage. Archives of General Psychiatry, 42, 636-637.

${ }^{10}$ Larsen, D. L., Attkisson, C. C., Hargreaves, W. A. \& NGuyen, T. D. (1979) Assessment of client/patient satisfaction; development of a general scale. Evaluation and Program Planning, 2, 197-207.

${ }^{11}$ Fink, P. J. \& Wenstenn, S. P. (1979) Whatever happened to psychiatry? The deprofessionalisation of Community Mental Health Centres. American Journal of Psychiatry, 136, 406-409. 